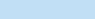

\title{
Vitamin A regulates hypothalamic- pituitary-adrenal axis status in LOU/C rats
}

\author{
Nathalie Marissal-Arvy ${ }^{1,2}$, Rachel Hamiani ${ }^{1,2}$, Emmanuel Richard ${ }^{3}$, \\ Marie-Pierre Moisan $^{1,2}$ and Véronique Pallet ${ }^{1,2}$ \\ ${ }^{1}$ INRA, Nutrition and Integrative Neurobiology, UMR1286, Université de Bordeaux 2, 146, rue Léo Saignat, \\ 33076 Bordeaux Cedex, France \\ ${ }^{2}$ Laboratory of Nutrition and Integrative Neurobiology, Univ. Bordeaux, UMR1286, 33076 Bordeaux Cedex, France \\ ${ }^{3}$ INSERM, Biothérapies des maladies génétiques et cancers, U1035, 33000 Bordeaux, France
}

\author{
Correspondence \\ should be addressed \\ to $\mathrm{N}$ Marissal-Arvy \\ Email \\ nathalie.arvy@bordeaux.inra.fr
}

\begin{abstract}
The aim of this study was to explore the involvement of retinoids in the hypoactivity and hyporeactivity to stress of the hypothalamic-pituitary-adrenal (HPA) axis in LOU/C rats. We measured the effects of vitamin A deficiency administered or not with retinoic acid (RA) on plasma corticosterone in standard conditions and in response to restraint stress and on hypothalamic and hippocampal expression of corticosteroid receptors, corticotropinreleasing hormone and $11 \beta$-hydroxysteroid dehydrogenase type 1 (11 $\beta$-HSD1) in LOU/C rats. Interestingly, under control conditions, we measured a higher plasma concentration of retinol in LOU/C than in Wistar rats, which could contribute to the lower basal activity of the HPA axis in LOU/C rats. Vitamin A deficiency induced an increased HPA axis activity in LOU/C rats, normalized by RA administration. Compared with LOU/C control rats, vitamin A-deficient rats showed a delayed and heightened corticosterone response to restraint stress. The expression of corticosteroid receptors was strongly decreased by vitamin A deficiency in the hippocampus, which could contribute to a less efficient feedback by corticosterone on HPA axis tone. The expression of $11 \beta$-HSD 1 was increased by vitamin A deficiency in the hypothalamus $(+62.5 \%)$ as in the hippocampus $(+104.7 \%)$, which could lead to a higher production of corticosterone locally and contribute to alteration of the hippocampus. RA supplementation treatment restored corticosterone concentrations and $11 \beta-H S D 1$ expression to control levels. The high vitamin A status of LOU/C rats could contribute to their low HPA axis activity/reactivity and to a protective effect against $11 \beta$-HSD1-mediated deleterious action on cognitive performances during ageing.
\end{abstract}

Journal of Endocrinology (2013) 219, 21-27

\section{Introduction}

Most of the vitamin A functions are performed by its active metabolite retinoic acid (RA), acting through nuclear receptors such as the RA receptors and the retinoid $\mathrm{X}$ receptors, all of which are transcription factors (Lefebvre et al. 2005). During adulthood, retinoids have

\author{
Key Words \\ - retinol \\ - glucocorticoid \\ - stress \\ - LOU/C \\ - rat
}


potentiation in the hippocampus, which is alleviated by the normalization of brain retinoid signalling by treatment with RA or nutritional vitamin A supplementation (Etchamendy et al. 2001, Mingaud et al. 2008). Glucocorticoid (GC) levels increase during ageing in rodents and humans, and this endocrine alteration results in prolonged exposure to excess GCs that compromise hippocampal plasticity and functions such as memory processes (Lupien et al. 2009). Thus, deficient retinoid activity and hyperactivity of GC co-occur during ageing and both have deleterious effects. While retinoid and glucocorticoid systems share at least partly the same targets such as brain-derived neurotrophic factor (Brossaud et al. 2013), only a few studies have explored the regulation of hypothalamic-pituitary-adrenal (HPA) axis function by retinoids. Previous studies have suggested an inhibition of glucocorticoid synthesis from cholesterol by vitamin A deficiency in rat adrenals (Juneja et al. 1966). Furthermore, RA treatment was shown to inhibit corticosterone (CORT) production in experimental Cushing's syndrome (Paez-Pereda et al. 2001). The inhibitory effect of retinoids on 11 $\beta$-hydroxysteroid dehydrogenase 1 (11 $\beta$-HSD1) expression, an enzyme that regenerates active GCs within cells, has been reported in liver and visceral fat of WNIN/Ob obese rats (Sakamuri et al. 2011), in adipose tissue of mice (Sakuta et al. 2006) and in vitro in myotubes (Aubry \& Odermatt 2009). This is interesting in regard to the fact that 11ß-HSD1 increases in the aged hippocampus and its elevated expression correlates with impaired spatial memory (Holmes et al. 2010).

We are particularly interested in the LOU/C-inbred rat strain, which was derived from the Wistar strain and has been described as a model of healthy ageing with a long life expectancy (Alliot et al. 2002) and preserved memory capacities (Kollen et al. 2010). This strain was shown not only to be lean but also to be resistant to age- and diet-induced obesity (Boghossian et al. 2002, Marissal-Arvy et al. 2011). Moreover, and in agreement with this phenotype, we showed that the HPA axis of LOU/C rats was hypoactive and hyporeactive to different stressors (Helies et al. 2005, Marissal-Arvy et al. 2007, 2011). This study aimed to explore the role played by retinoids in the hypoactivity and hyporeactivity of the HPA axis in LOU/C rats. For the first time, we measured the effects of vitamin A deficiency on plasma corticosterone under standard conditions and in response to restraint stress and on hypothalamic and hippocampal expression of corticosteroid receptors (mineralocorticoid (MR) and glucocorticoid (GR) receptors), corticotropin-releasing hormone $(\mathrm{CRH})$ and $11 \beta-\mathrm{HSD} 1$ in LOU/C rats.

\section{Materials and methods}

\section{Animals}

All animal experiments were conducted according to the INRA Quality Reference System and to relevant French (Directive 87/148, Ministère de l'Agriculture et de la Pêche) and international (Directive 86/609, November 24th 1986, European Community) legislation. Experiments followed procedures approved by Région Aquitaine Veterinary Services (Direction Départementale de la Protection des Animaux, approval ID: A33-063-920). Our local ethics committee specifically approved this study. Every effort was made to minimize suffering and the number of animals used. Wistar rats were purchased from Janvier (Saint Berthevin, France) and were used concomitantly in another study. In this study, 24 Wistar rats were used for retinol measurements only. Plasma collections were performed on age-matched Wistar and LOU/C rats for subsequent retinol assays. Weaning male LOU/C rats (3-week old) were bred in our laboratory and were housed two per cage in a room with a constant airflow system, controlled temperature $\left(21-23^{\circ} \mathrm{C}\right.$ ) and a $12 \mathrm{~h}$ light: $12 \mathrm{~h}$ darkness cycle (lights on at $0700 \mathrm{~h}$ ). Rats were given access to food and water ad libitum and were randomly divided into experimental groups. One group $(n=24)$ received a vitamin A-free diet (Laboratorio Piccionni, Italy) whereas the control group $(n=12)$ was fed a control diet containing 6.6 IU retinol/g (UAR04 Safe, Les Tremblats, France) for 10 weeks. The control diet used was similar to the vitamin A-deficient diet for all constituents except vitamin A/retinol. During the last week, half of the vitamin A-deficient group was injected daily with RA (150 $\mu \mathrm{g}$ of all-trans-RA/kg, Sigma) and the remaining vitamin A-deficient and the control rats were injected with vehicle (polyethyleneglycol-NaCl-ethanol 70:20:10 by volume). On the fifth day of RA treatment, tail bleeds were performed on all rats in the morning (1000-1100 h) and in the evening (1800-1900 h), and blood was collected in EDTA-coated tubes. Blood was centrifuged at $4000 \mathrm{~g}$ for $10 \mathrm{~min}$ at $4{ }^{\circ} \mathrm{C}$ in order to extract the plasma.

Half of the rats from each of the three groups ( $n=6$ /group) were subjected to a restraint stress in plastic bags with a breathing hole (Harvard Apparatus, Ealing, Courtaboeuf, France) for 20 min between 0900 and $1100 \mathrm{~h}$ on the sixth day of RA treatment. Blood samples were collected from a nick of the tail for the measurement of basal (T0), stress peak (T60 and T90) and recovery (T120) values of plasma corticosterone concentration (times were chosen following our previous results (Sarrieau \& Mormede 1998, Marissal-Arvy et al. 2007)).

Published by Bioscientifica Ltd. 
At the end of the experiment, in the morning (0900-1200 h), the rats were killed by decapitation. Cerebral tissues were dissected on an ice bed and all samples were stored at $-80^{\circ} \mathrm{C}$ until utilization.

\section{Plasma retinol}

Analysis of plasma retinol was performed by isocratic phase HPLC as described previously (Urbanek et al. 2006). Briefly, internal standard solution ( $\alpha$-tocopherol) and plasmatic retinol were extracted using hexane solution supplemented with butylated hydroxytoluene (BHT) as an antioxidant. Chromatography was performed on a C-18 HPLC column with methanol as the mobile phase $(1.2 \mathrm{ml} / \mathrm{min})$. Retinol was detected by u.v. absorbance at $325 \mathrm{~nm}$ (Surveyor, Thermo Scientific, Courtaboeuf, France).

\section{Plasma corticosterone}

Plasma corticosterone was measured with an in-house RIA (Richard et al. 2010) using a highly specific antibody provided by H Vaudry (University of Rouen, France). Briefly, after steroid extraction of plasma samples with absolute ethanol, total corticosterone was measured by competition between cold corticosterone and ${ }^{3} \mathrm{H}$-corticosterone by our specific antibody anti-corticosterone.

\section{Central expression of genes}

The levels of mRNA were measured by real-time RT-PCR using SYBR green 1 as the fluorescent marker (Holland et al. 1991). Total RNA was extracted from the hypothalamus and hippocampus with a Trizol extraction kit (Invitrogen). RNAs were quantified on a nanodrop 1000 (Thermo Scientific) and their quality was estimated on Agilent RNA 6000 nano chips with an Agilent 2100 Bioanalyzer. RT was made on aliquots of total RNA $(2 \mu \mathrm{g})$ using a Superscript III Invitrogen kit. Sequences of the primers used were for CRH F-CCTTCTGAGGGAAGTCTTGGAAAT, R-TGCTGTGAGCTTGCTGAGCTA, for MR F-CTTTACGAAGTGTTTCTACTGGATCCT, R-TGACACCCAGAAGCCTCATCT, for GR F-GGGACCACCTCCCAAGCT, R-ACCCCGTAATGACATCCTGAAG and for 11ß-HSD1 F-TGGAAGACATGGCTTTTGCA, R-TCCAGTCCACCCAAGAGCTT. Each sample of cDNA was randomly measured on duplicates of $4 \mathrm{ng}$ for the target and housekeeping genes. Real-time PCR was performed with Opticon 2 Bio-Rad Software (MJ Research) using DynamoTM HS SYBR Green qPCR kit Finnzymes (Ozyme,
St Quentin en Yvelines, France). The reaction was performed at $95{ }^{\circ} \mathrm{C}$ for $15 \mathrm{~min}$ followed by 40 cycles at $95^{\circ} \mathrm{C}$ for $20 \mathrm{~s}$ and $61^{\circ} \mathrm{C}$ for $35 \mathrm{~s}$. The expression level of each gene was calculated as $\Delta C \mathrm{~T}$, which was calculated by subtracting CT (control gene: enolase 2) from $C \mathrm{~T}$ (target gene). The relative expression level of the target gene was expressed as $2^{-\Delta \Delta C T}$, when compared with the mean $\Delta C T$ of the control group. ANOVA (one-way: diet) was made on the values of $\Delta C T$ and were considered as significant when $P<0.05$. Figures show the $2^{-\Delta \Delta C \mathrm{~T}}$ (=fold-change, mean \pm s.E.M.).

\section{Statistical analysis}

Results were expressed as mean \pm s.e.m. Data were submitted to one- or two-way ANOVA (treatment and time as repeated factor when appropriate). When ANOVA was significant $(P<0.05)$, post hoc comparisons were performed using the Newman-Keuls test.

\section{Results}

\section{Body weight in LOU/C}

ANOVA showed a time effect $(P<0.001)$ and a time $\times$ diet interaction $(P<0.001)$. The growth of vitamin A-deficient rats was slowed down from the third week of diet and the seventh week of age $(P<0.001$, Fig. 1$)$. We made the choice to maintain the LOU/C rats under vitamin A deficiency during 10 weeks as classically performed in Wistar rats (in whom a plateau in weight curve appears at 10 weeks of deficiency (Husson et al. 2003, 2006)).

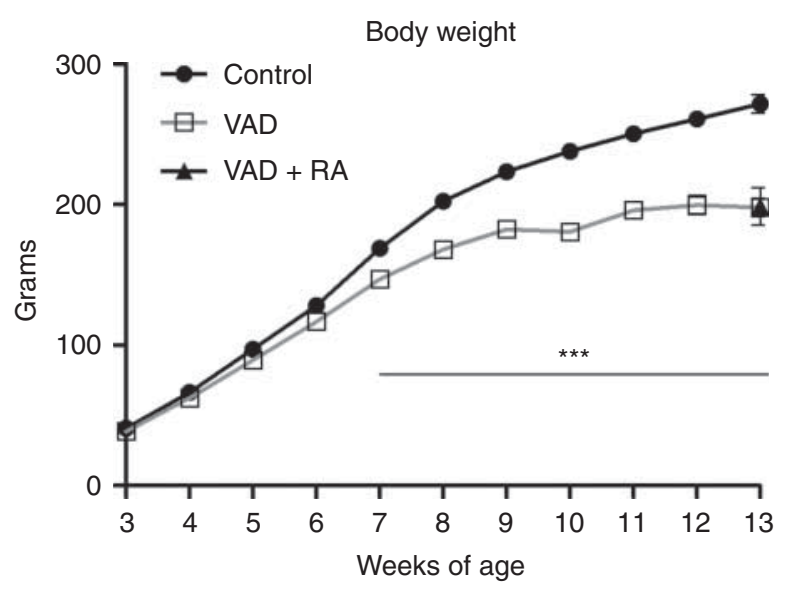

Figure 1

Body weight gain of LOU/C rats during the experimental period. Vitamin A-deficient (VAD) rats had a lower body weight than control rats from the third week of $\operatorname{diet}(* * * P<0.001), n=12$ per group.

Published by Bioscientifica Ltd. 


\section{Plasma retinol in LOU/C vs Wistar rats}

ANOVA revealed a strain effect when LOU/C rats were compared with the Wistar rats. Plasma retinol was $11.6 \%$ higher in LOU/C than in Wistar rats (Fig. 2) under control conditions $(P<0.01)$.

\section{Plasma corticosterone in LOU/C rats}

At the beginning of the inactive phase (in the morning) and at the beginning of the active phase (in the evening), vitamin A deficiency increased plasma corticosterone (154.5\%, $P<0.01$ and $82.3 \%, P<0.001$ respectively, Fig. 3A). These values were returned to the control level by RA treatment.

For the stress response, ANOVA showed a diet effect $(P<0.001)$ and a time $\times$ diet interaction $(P<0.001)$. Corticosterone response to stress was blunted in control LOU/C rats whereas vitamin A-deficient rats showed a significant peak at $90 \mathrm{~min}(P<0.001$, Fig. 3B). Plasma corticosterone 90 and $120 \mathrm{~min}$ after the beginning of the restraint stress was higher in the vitamin A-deficient group (by 144.5 and $131.0 \%$ respectively) than in the control group. RA restored plasma corticosterone of vitamin A-deficient rats to the control level. We did not measure a return to basal values $120 \mathrm{~min}$ post-stress.

\section{Central expression of genes in LOU/C rats}

In the hypothalamus, no change was revealed for MR, GR or CRH expression (Fig. 4A). Vitamin A deficiency increased hypothalamic 11 $\beta$-HSD1 expression $(62.5 \%$,

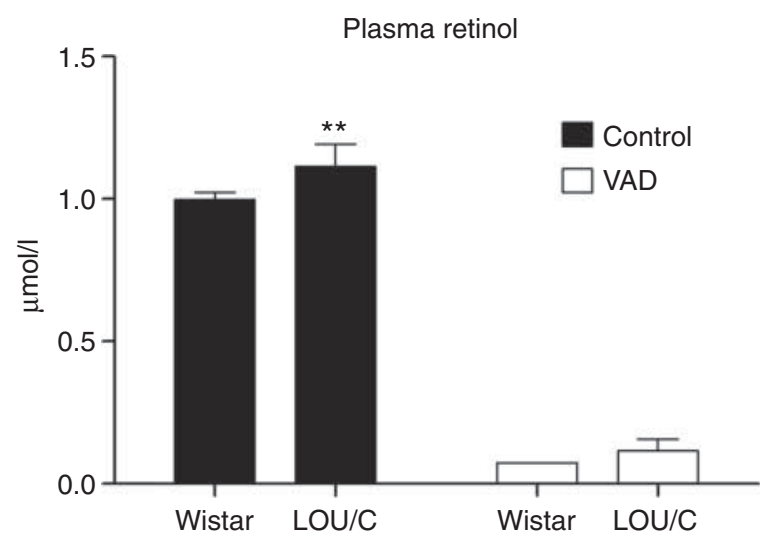

Figure 2

Plasma retinol in Wistar rats ( $n=12$ controls and $n=12$ VAD) and LOU/C rats ( $n=12$ controls and $n=22$ VAD). Under control conditions, plasma retinol was higher in LOU/C rats than in Wistar rats $(* * P<0.01)$.
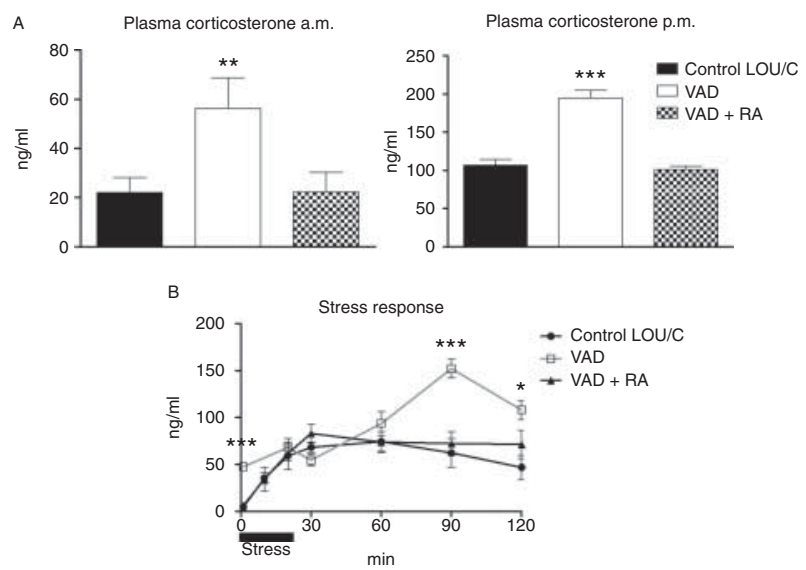

\section{Figure 3}

(A) Plasma corticosterone at the nadir (a.m.) and at the zenith (p.m.) of secretion across the circadian cycle in LOU/C rats ( $n=10-12$ per group). In both cases, vitamin A-deficient (VAD) rats showed higher plasma corticosterone levels than the control rats or the VAD + RA LOU/C rats. (B) Plasma corticosterone in response to restraint stress $(n=5-6$ per group). VAD LOU/C rats showed higher and shifted reactivity to stress compared with LOU/C control rats, VAD corrected by RA. ${ }^{\star} P<0.05$; $* * P<0.01 ; * * * P<0.001$.

$P<0.01)$ and RA treatment recapitulated control 11 $\beta-H S D 1$ expression levels.

In the hippocampus, ANOVA showed a treatment effect for MR, GR $(P<0.01)$ and 11 $\beta$-HSD1 $(P<0.001)$ expressions. MR and GR expressions were decreased by 24.7 and $71.0 \%$ respectively, whereas $11 \beta$-HSD1 was increased by $104.7 \%$ by vitamin A deficiency (Fig. 4B). RA treatment restored these expressions to the control values.

\section{Discussion}

The aim of this study was to explore the involvement of retinoids in the functional specificities of the HPA axis of LOU/C rats. In relation to their leanness, their long life expectancy and their preserved cognitive capacities with age, we previously characterized a HPA axis hypoactive and hyporesponsive to environmental or metabolic challenges in LOU/C rats (Marissal-Arvy et al. 2007, 2011). The phenotype of LOU/C rats may be related to the functional properties of the retinoid system, with vitamin A mediating a reduction in adipogenesis (Mercader et al. 2006, Ziouzenkova et al. 2007) and protective effects against memory impairments during ageing (Etchamendy et al. 2001, Bonnet et al. 2008, Mingaud et al. 2008). We then aimed to test whether vitamin A could be a regulator of the HPA axis in LOU/C rats. We studied the functional consequences on the HPA axis of vitamin A deficiency corrected or not with RA treatment in LOU/C rats.

Published by Bioscientifica Ltd. 

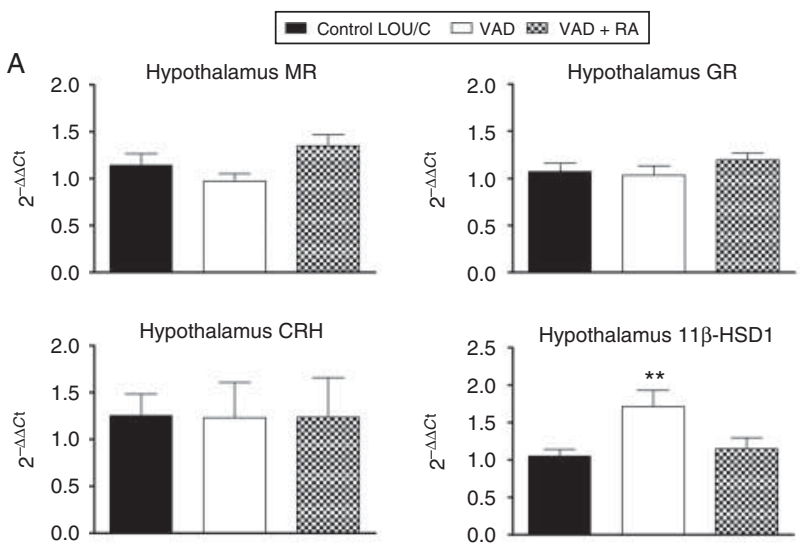

B
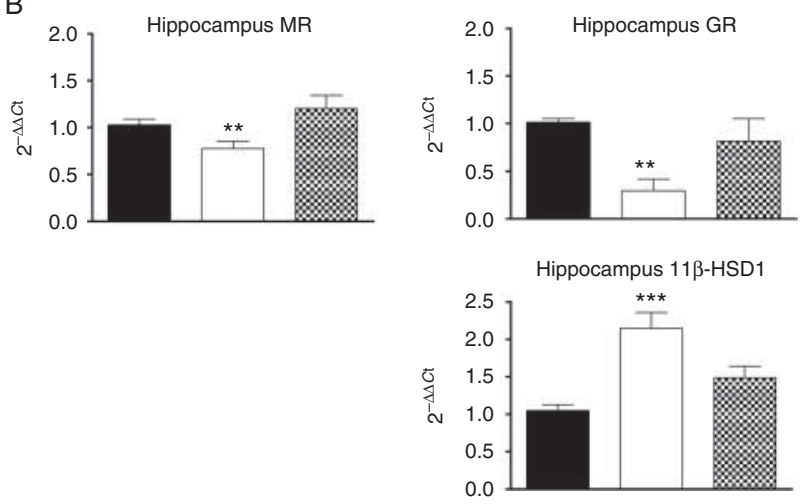

Figure 4

MR, GR, CRH and 11 $\beta$-HSD1 expressions in the hypothalamus (A) and MR, GR and $11 \beta$-HSD1 expressions in the hippocampus (B) in LOU/C rats ( $n=10-12$ per group). The vitamin A-deficient (VAD) group expressed more hypothalamic $11 \beta$-HSD1 when compared with control and VAD + RA groups. The VAD rats expressed more hippocampal 11 $\beta$-HSD1 and less hippocampal MR and GR when compared with control and VAD + RA rats. $* * P<0.01 ; * * * P<0.001$.

Contrary to what was described in Wistar rats (Husson et al. 2003, 2006), the weight growth of LOU/C rats was slowed down very quickly by the vitamin A deficiency. The RA treatment lasted 1 week only and was not sufficient to restore the weight gain. The leanness of LOU/C rats made them perhaps more vulnerable to the metabolic disorders induced by the vitamin A deficiency. We had to choose arbitrarily a duration of vitamin A deficiency of 10 weeks, as we had for point of reference no drop out of the weight curve as observed in Wistar rats after $\sim 6-7$ weeks of diet.

We measured a higher plasma retinol concentration in LOU/C than in Wistar rats under control conditions. This higher concentration could be due to a lower clearance of retinoids in LOU/C rats, a greater intestinal absorption of vitamin A or a regular release from greater hepatic stores. Further investigations are needed to answer this question.
We explored the effect of vitamin A deficiency on HPA axis activity and reactivity to restraint stress in LOU/C rats. We first measured plasma corticosterone in basal inactive and active phases of the circadian rhythm. In both cases, the vitamin A deficiency induced an increase in HPA axis activity, which was restored to control level by the supplementation treatment with RA. These results suggest that there exists a close relationship between vitamin A status and corticosterone synthesis, which seems to be an antagonism in our model. The increase in plasma corticosterone could involve an increased expression of hypothalamic CRH, an increased pituitary secretion of adrenocorticotropic hormone (ACTH), an increased sensitivity of the adrenals to ACTH and/or an altered central feedback exerted by corticosterone on its receptors, MR and GR.

In the aim to test the effect of vitamin A deficiency on HPA axis reactivity to environmental stress, we measured plasma corticosterone in response to restraint stress in our rats. As we showed previously (Marissal-Arvy et al. 2007), stress reactivity to restraint was blunted in LOU/C control rats. On the contrary, LOU/C vitamin A-deficient rats showed a standard corticosterone response to a restraint stress, when compared with other rat strains (Marissal-Arvy et al. 2007), however with a delayed secretion peak $90 \mathrm{~min}$ post-stress for which we have no explanation. RA treatment restored corticosterone concentrations to the control level. The time point 120 min was not sufficient for the return of plasma corticosterone to the basal level. Our results are in contradiction with the results of Cai et al. (2010), which showed that chronic all-trans RA administration induced hyperactivity of the HPA axis in rats. However, these authors used supraphysiological doses of all-trans RA in intact young rats whereas we have injected physiological doses of RA in vitamin A-deficient adult rats. These differences in RA dose and animals' age and nutritional status may explain the discrepancy between our results and those of Cai's group. Hypothalamic expression of $\mathrm{CRH}$ was not modified by vitamin A deficiency, which suggests that another mechanism is responsible for the increased HPA axis activity and reactivity in response to vitamin A deficiency in LOU/C rats. The expression of MR and GR was not modified by vitamin A deficiency in the hypothalamus, contrary to the hippocampus in which MR and GR expression was significantly decreased by vitamin A deficiency. This could contribute to a less efficient feedback by corticosterone on HPA axis tone. The treatment with RA for 1 week was sufficient to counteract the vitamin A deficiency effect and to return

Published by Bioscientifica Ltd 
the expressions to the control levels, as was the case for plasma corticosterone.

The expression of $11 \beta-H S D 1$ was increased by vitamin A deficiency in the hypothalamus as in the hippocampus. This effect was retinoid specific as RA treatment reversed vitamin A deficiency effects on 11ß-HSD1 expression. The inhibitory effect of retinoids on 11 $\beta$-HSD1 expression has been already shown peripherally in liver and visceral fat of WNIN/Ob obese rats (Sakamuri et al. 2011), in adipose tissue of mice (Sakuta et al. 2006) and in vitro in myotubes (Aubry \& Odermatt 2009) but never in central structures. Within the cell, 11ß-HSD1 catalyses the regeneration of active glucocorticoid, thus amplifying glucocorticoid action. The high vitamin A status of LOU/C rats may confer protection against 11ß-HSD1-mediated deleterious action on cognitive performance with age. Indeed, Holmes et al. (2010) showed that an increased hippocampal expression of 11ß-HSD1 was responsible for memory impairments in mice. Partial deficiency or short-term inhibition of $11 \beta$-HSD1 improves cognitive function in ageing mice (Sooy et al. 2010). The fact that vitamin A deficiency induces anatomic and phenotypic changes comparable with those in neurodegeneration (Ghenimi et al. 2009) could be partly linked to an increase in 11ß-HSD1 expression at the central level.

In conclusion, vitamin A deficiency effects in LOU/C rats suggest the involvement of vitamin $\mathrm{A}$ in the specificities of their HPA axis. By its inhibiting effects on MR and GR hippocampal expressions, vitamin A deficiency may induce a less efficient negative feedback exerted by corticosterone on the HPA axis, as suggested by the increased plasma corticosterone under basal conditions and in response to restraint stress. The inhibition of central expression of $11 \beta$-HSD1 by retinoids could contribute to their protective effect on cognitive function during ageing.

\section{Declaration of interest}

The authors declare that there is no conflict of interest that could be perceived as prejudicing the impartiality of the research reported.

\section{Funding}

This research did not receive any specific grant from any funding agency in the public, commercial or not-for-profit sector.

\section{Author contribution statement}

$\mathrm{N} \mathrm{M-A} \mathrm{designed} \mathrm{the} \mathrm{experiments} \mathrm{and} \mathrm{wrote} \mathrm{the} \mathrm{manuscript.} \mathrm{R} \mathrm{H}$ took care of the animals. E R measured plasma retinol. M-P M and V P supervised the work and corrected the manuscript.

\section{Acknowledgements}

The authors thank Thierry Leste-Lassere and Guillaume Drutel for their useful advice about qPCR.

\section{References}

Alliot J, Boghossian S, Jourdan D, Veyrat-Durebex C, Pickering G, Meynial-Denis D \& Gaumet N 2002 The LOU/c/jall rat as an animal model of healthy aging? Journals of Gerontology. Series A, Biological Sciences and Medical Sciences 57 B312-B320. (doi:10.1093/gerona/57. 8.B312)

Aubry EM \& Odermatt A 2009 Retinoic acid reduces glucocorticoid sensitivity in C2C12 myotubes by decreasing $11 \beta$-hydroxysteroid dehydrogenase type 1 and glucocorticoid receptor activities. Endocrinology 150 2700-2708. (doi:10.1210/en.2008-1618)

Boghossian S, Nzang Nguema G, Jourdan D \& Alliot J 2002 Old as mature $\mathrm{LOU} / \mathrm{c} / \mathrm{jall}$ rats enhance protein selection in response to a protein deprivation. Experimental Gerontology 37 1431-1440. (doi:10.1016/ S0531-5565(02)00174-2)

Bonnet E, Touyarot K, Alfos S, Pallet V, Higueret P \& Abrous DN 2008 Retinoic acid restores adult hippocampal neurogenesis and reverses spatial memory deficit in vitamin A deprived rats. PLoS ONE 3 e3487. (doi:10.1371/journal.pone.0003487)

Brossaud J, Roumes H, Moisan MP, Pallet V, Redonnet A \& Corcuff JB 2013 Retinoids and glucocorticoids target common genes in hippocampal HT22 cells. Journal of Neurochemistry 125 518-531. (doi:10.1111/jnc.12192)

Cai L, Yan XB, Chen XN, Meng QY \& Zhou JN 2010 Chronic all-trans retinoic acid administration induced hyperactivity of HPA axis and behavioral changes in young rats. European Neuropsychopharmacology 20 839-847. (doi:10.1016/j.euroneuro.2010.06.019)

Etchamendy N, Enderlin V, Marighetto A, Vouimba RM, Pallet V, Jaffard R \& Higueret P 2001 Alleviation of a selective age-related relational memory deficit in mice by pharmacologically induced normalization of brain retinoid signaling. Journal of Neuroscience 21 6423-6429.

Ghenimi N, Beauvieux MC, Biran M, Pallet V, Higueret P \& Gallis JL 2009 Vitamin A deficiency in rats induces anatomic and metabolic changes comparable with those of neurodegenerative disorders. Journal of Nutrition 139 696-702. (doi:10.3945/jn.108.102988)

Helies JM, Diane A, Langlois A, Larue-Achagiotis C, Fromentin G, Tome D, Mormede P \& Marissal-Arvy N 2005 Comparison of fat storage between Fischer 344 and obesity-resistant Lou/C rats fed different diets. Obesity Research 13 3-10. (doi:10.1038/oby.2005.3)

Holland PM, Abramson RD, Watson R \& Gelfand DH 1991 Detection of specific polymerase chain reaction product by utilizing the $5^{\prime}-3^{\prime}$ exonuclease activity of Thermus aquaticus DNA polymerase. PNAS $\mathbf{8 8}$ 7276-7280. (doi:10.1073/pnas.88.16.7276)

Holmes MC, Carter RN, Noble J, Chitnis S, Dutia A, Paterson JM, Mullins JJ, Seckl JR \& Yau JL 2010 11ß-Hydroxysteroid dehydrogenase type 1 expression is increased in the aged mouse hippocampus and parietal cortex and causes memory impairments. Journal of Neuroscience 30 6916-6920. (doi:10.1523/JNEUROSCI.0731-10.2010)

Husson M, Enderlin V, Alfos S, Feart C, Higueret P \& Pallet V 2003 Triiodothyronine administration reverses vitamin A deficiency-related hypo-expression of retinoic acid and triiodothyronine nuclear receptors and of neurogranin in rat brain. British Journal of Nutrition 90 191-198. (doi:10.1079/BJN2003877)

Husson M, Enderlin V, Delacourte A, Ghenimi N, Alfos S, Pallet V \& Higueret P 2006 Retinoic acid normalizes nuclear receptor mediated hypo-expression of proteins involved in $\beta$-amyloid deposits in the cerebral cortex of vitamin A deprived rats. Neurobiological Disorders 23 1-10. (doi:10.1016/j.nbd.2006.01.008)

Juneja HS, Murthy SK \& Ganguly J 1966 The effect of vitamin A deficiency on the biosynthesis of steroid hormones in rats. Biochemical Journal 99 138-145.

Published by Bioscientifica Ltd. 
Kollen M, Stephan A, Faivre-Bauman A, Loudes C, Sinet PM, Alliot J, Billard JM, Epelbaum J, Dutar P \& Jouvenceau A 2010 Preserved memory capacities in aged Lou/C/Jall rats. Neurobiology of Aging 31 129-142. (doi:10.1016/j.neurobiolaging.2008.03.010)

Lane MA \& Bailey SJ 2005 Role of retinoid signalling in the adult brain. Progress in Neurobiology 75 275-293. (doi:10.1016/j.pneurobio. 2005.03.002)

Lefebvre P, Martin PJ, Flajollet S, Dedieu S, Billaut X \& Lefebvre B 2005 Transcriptional activities of retinoic acid receptors. Vitamins and Hormones 70 199-264.

Lupien SJ, McEwen BS, Gunnar MR \& Heim C 2009 Effects of stress throughout the lifespan on the brain, behaviour and cognition. Nature Reviews. Neuroscience 10 434-445. (doi:10.1038/nrn2639)

Marissal-Arvy N, Gaumont A, Langlois A, Dabertrand F, Bouchecareilh M, Tridon C \& Mormede P 2007 Strain differences in hypothalamic pituitary adrenocortical axis function and adipogenic effects of corticosterone in rats. Journal of Endocrinology 195 473-484. (doi:10.1677/JOE-07-0077)

Marissal-Arvy N, Langlois A, Tridon C \& Mormede P 2011 Functional variability in corticosteroid receptors is a major component of strain differences in fat deposition and metabolic consequences of enriched diets in rat. Metabolism 60 706-719. (doi:10.1016/j.metabol. 2010.07.005)

Mercader J, Ribot J, Murano I, Felipe F, Cinti S, Bonet ML \& Palou A 2006 Remodeling of white adipose tissue after retinoic acid administration in mice. Endocrinology 147 5325-5332. (doi:10.1210/en.2006-0760)

Mingaud F, Mormede C, Etchamendy N, Mons N, Niedergang B, Wietrzych M, Pallet V, Jaffard R, Krezel W, Higueret P et al. 2008 Retinoid hyposignaling contributes to aging-related decline in hippocampal function in short-term/working memory organization and long-term declarative memory encoding in mice. Journal of Neuroscience 28 279-291. (doi:10.1523/JNEUROSCI.4065-07.2008)

Paez-Pereda M, Kovalovsky D, Hopfner U, Theodoropoulou M, Pagotto U, Uhl E, Losa M, Stalla J, Grubler Y, Missale C et al. 2001 Retinoic acid prevents experimental Cushing's syndrome. Journal of Clinical Investigation 108 1123-1131.

Richard EM, Helbling JC, Tridon C, Desmedt A, Minni AM, Cador M, Pourtau L, Konsman JP, Mormede P \& Moisan MP 2010 Plasma transcortin influences endocrine and behavioral stress responses in mice. Endocrinology 151 649-659. (doi:10.1210/en.2009-0862)

Sakamuri VP, Ananthathmakula P, Veettil GN \& Ayyalasomayajula V 2011 Vitamin A decreases pre-receptor amplification of glucocorticoids in obesity: study on the effect of vitamin A on 11ß-hydroxysteroid dehydrogenase type 1 activity in liver and visceral fat of WNIN/Ob obese rats. Nutrition Journal 10 70. (doi:10.1186/1475-2891-10-70)

Sakuta T, Uchiyama T \& Kanayama T 2006 Topical ER36009, a RARgammaselective retinoid, decreases abdominal white adipose tissue and elicits changes in expression of genes related to adiposity and thermogenesis. Endocrine 30 113-119. (doi:10.1385/ENDO:30:1:113)

Sarrieau A \& Mormede P 1998 Hypothalamic-pituitary-adrenal axis activity in the inbred Brown Norway and Fischer 344 rat strains. Life Sciences 62 1417-1425. (doi:10.1016/S0024-3205(98)00080-0)

Sooy K, Webster SP, Noble J, Binnie M, Walker BR, Seckl JR \& Yau JL 2010 Partial deficiency or short-term inhibition of 11ß-hydroxysteroid dehydrogenase type 1 improves cognitive function in aging mice. Journal of Neuroscience 30 13867-13872. (doi:10.1523/JNEUROSCI. 2783-10.2010)

Urbanek L, Solichova D, Melichar B, Dvorak J, Svobodova I \& Solich P 2006 Optimization and validation of a high performance liquid chromatography method for the simultaneous determination of vitamins A and $\mathrm{E}$ in human serum using monolithic column and diode-array detection. Analytica Chimica Acta 573-574 267-272. (doi:10.1016/j. aca.2006.02.032)

Ziouzenkova O, Orasanu G, Sharlach M, Akiyama TE, Berger JP, Viereck J, Hamilton JA, Tang G, Dolnikowski GG, Vogel S et al. 2007 Retinaldehyde represses adipogenesis and diet-induced obesity. Nature Medicine 13 695-702. (doi:10.1038/nm1587)

Received in final form 5 July 2013

Accepted 11 July 2013

Accepted Preprint published online 11 July 2013
(ㄷ) 2013 Society for Endocrinology Printed in Great Britain 